\title{
Bearing damage characterization using SVAN 958 and laser in the time domain
}

\author{
S.A. Aye \\ Dynamic Systems Group (DSG), Department of Mechanical and Aeronautical Engineering, \\ University of Pretoria, Pretoria, 0002, South Africa \\ sylvester.aye@up.ac.za
}

\begin{abstract}
The study evaluated bearing damage detection using SVAN 958 and laser. Accelerometers attached to SVAN 958 were used to measure the radial accelerations from the bearing housing. The laser which is an optical device was then subsequently used to measure the radial accelerations from the bearing housing. The data obtained from the two measuring techniques was processed to detect damage of the bearing using statistical tools and it was established that both methodologies were able to detect damage in the bearing.
\end{abstract}

Key Words: bearing, damage detection, statistical tools, SVAN 958, laser

\section{INTRODUCTION}

The failure of bearings is one of the primary initiators of rotating machinery breakdowns which results in costly shutdowns. One of the major concerns in bearing diagnostics is the detection of the defect at its incipient stage and subsequently alerting the operator before it develops into a catastrophic failure ${ }^{1}$. The ability to achieve accurate bearing diagnostics is essential to the optimal maintenance of rotating equipment with respect to cost and productivity. The study investigated the effectiveness of the SVAN 958 and laser methods in the early detection of incipient faults.

The statistical analysis method utilizing parameters such as crest factor, the distribution of moments and kurtosis were used to detect the presence of defects in a rolling element bearing applying sound pressure and vibration signals ${ }^{2}$. The statistical analysis method was used because of its simplicity and quick computation. A statistical analysis method is most suitable with random signals where other signal analysis methods based on the assumptions of deterministic signals are not applicable. The effect of shaft speed on the performance of the statistical method was also studied. The results from the study showed that the statistical parameters were affected by the shaft speed due to the sensitivity of the bearing housing components to a longitudinal vibration that excites the fixing ring which holds the test bearing in its position. Under ideal conditions, the statistical method can be used to identify the different types of defect present in the bearing.

The statistical parameter kurtosis remains constant for an undamaged bearing irrespective of load and speed, yet changes with damage ${ }^{3}$. Normally bearing vibration are measured on the bearing housing using accelerometers. The extent of damage can be assessed from the distribution of this statistical parameter in selected frequency ranges. An assessment of bearing condition can thus be made with minimum recourse to historical information. Most other damage detection techniques rely heavily on the trend analysis of data and so the statistical method proves to be a significant advance in bearing fault detection technology, at least when viewed within the objective to provide a simple and cheap technique. As with most other simple detection techniques, the precise nature of the fault cannot be defined and for such information it is necessary to use the more sophisticated diagnostic methods.

\section{METHODOLOGY}

Few studies ${ }^{4,5}$ have used laser Doppler vibrometry to measure velocities which are then analysed to detect bearing defects. The Sound and Vibration Analyzer (SVAN) 958 was used to measure whole body vibrations on the seat of mine vehicles ${ }^{6}$. However, no study has used SVAN 958 to measure bearing vibration from bearing housing in order to detect bearing damage. This study evaluated bearing damage using SVAN 958 and laser methods to measure accelerations on the bearing housing. Accelerometers attached to the SVAN 958 were used to measure the radial 
accelerations from the bearing housing as shown in figure 1. The data obtained was then processed using MATLAB based software. The statistical approach was used in processing and analysis of the data for damage detection and assessment of the bearing. The peak, root mean square (RMS), crest factor and kurtosis were used in the statistical approach. Subsequently the laser which is an optical device was then used to measure the radial accelerations from the bearing housing as shown in figure 2 . The data obtained was equally processed to detect damage of the bearing using the statistical approach as enunciated above. The results from the SVAN 958 and the laser were subsequently compared as to which of the methods is capable of detecting bearing faults in various scenarios. Trending at various statistical parameters for the two methodologies was also investigated. The trending of the measurements was in the radial directions and at the three positions as shown in figure 1.

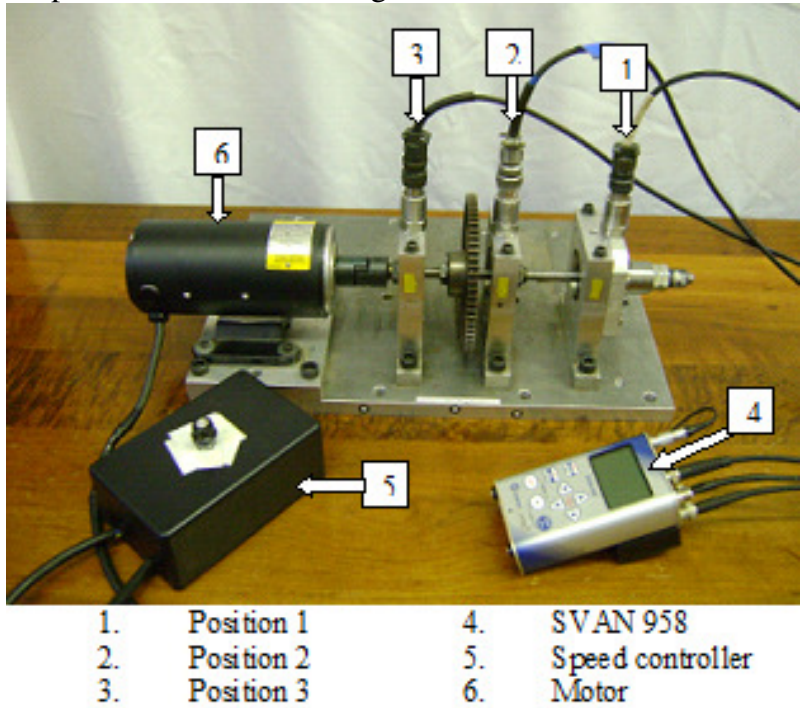

FIGURE 1. Measurement with Accelerometers and SVAN 958

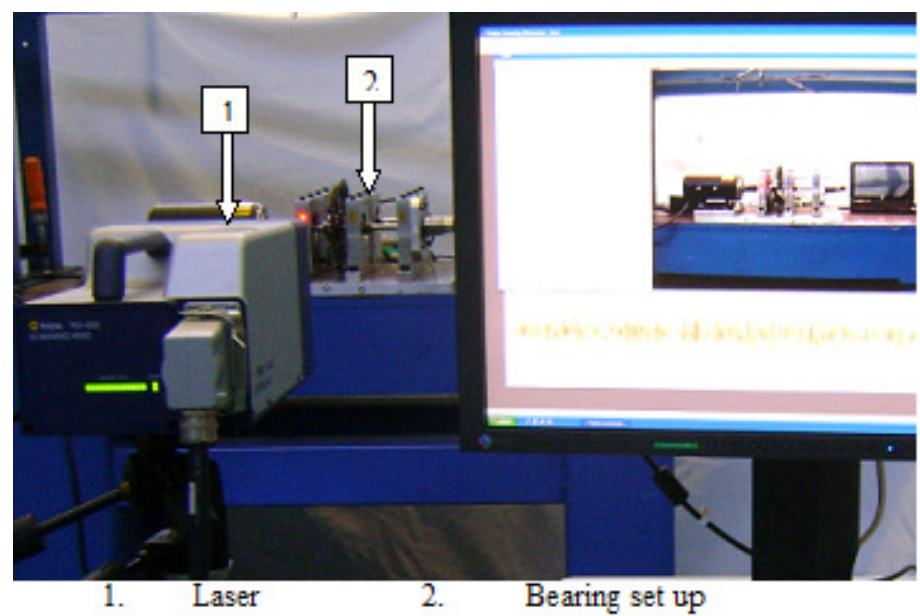

FIGURE 2. Measurement with laser

The vibration data waveform is analyzed in the time domain for impacts that correspond to the rotation of the rolling elements past the damage for each shaft revolution. Time domain statistical parameters such as RMS, peak, crest factor, and kurtosis shown in equations 1-4 are calculated for the time domain data obtained using both the accelerometers attached to the SVAN 958 and the laser. As the damage occurs, an increase in these values should occur. The bearing time domain metrics are calculated based on the following equations where $\bar{x}$ equals the mean value of the time signal $x(t)$ having $N$ data points ${ }^{7}$. 


$$
\begin{aligned}
& \text { peak }=\frac{1}{2}(\max (x(t))-\min (x(t))) \\
& R M S=\sqrt{\frac{1}{N} \sum_{i=1}^{N}(x(i)-\bar{x})^{2}} \\
& \text { CrestFactor }=\frac{\text { peak }}{R M S} \\
& \text { Kurtosis }=\frac{\sqrt{\frac{1}{N} \sum_{i=1}^{N}(x(i)-\bar{x})^{4}}}{R M S^{4}}
\end{aligned}
$$

\section{RESULTS}

Accelerometers attached to the SVAN 958 were used to measure the vertical (y-direction) radial accelerations from the bearing housing as shown in figure 1 and the sample time domain acceleration plot for one of the measurements is shown in figure 3 (a) for position 2 at $504 \mathrm{rpm}$. The data obtained from the measurements was then processed using MATLAB based software to obtain the statistical parameters for positions 1-3 at the various speeds. The computed statistical parameters are the peak, RMS, crest factor and kurtosis which are tabulated as shown in tables 1-2 for positions 1-3 respectively. Similarly the laser which is an optical device was then used to measure the horizontal (z-direction) radial accelerations from the bearing housing and a sample time domain data plot is shown in figure 3 (b) for position 2 at $504 \mathrm{rpm}$. The data obtained from the measurements was equally processed at various speeds and the statistical parameters such as the peak, RMS, crest factor and kurtosis were obtained and tabulated as shown in tables 3-4 for positions 1-3 respectively.

(a)

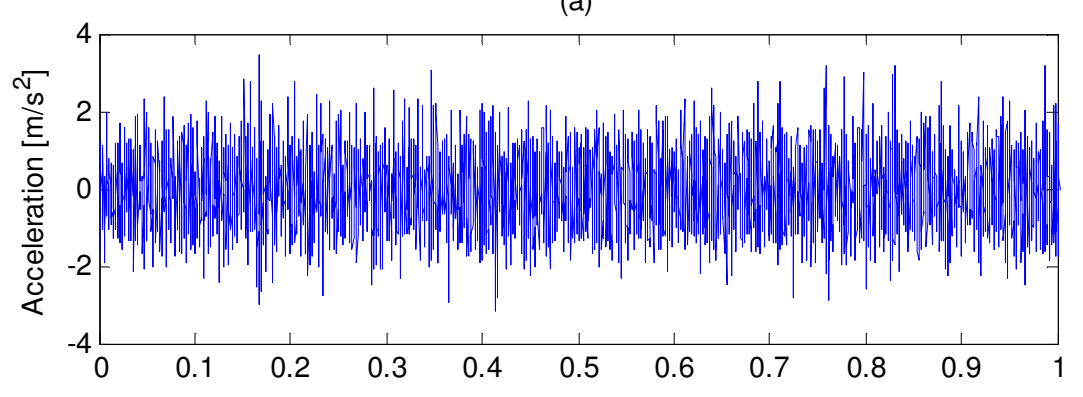

(b)



FIGURE 3. Time data from (a) Accelerometer with SVAN 958 and (b) laser 
TABLE 1. Statistical parameters from the laser vibrometer on position 1 and 2

\begin{tabular}{lllllllll}
\hline & Position 1 & & & \multicolumn{4}{c}{ Position 2 } \\
\hline $\begin{array}{l}\text { Speed } \\
\mathbf{r p m})\end{array}$ & $\begin{array}{l}\text { Peak } \\
\left(\mathbf{m} / \mathbf{s}^{\mathbf{2}}\right)\end{array}$ & $\begin{array}{l}\text { RMS } \\
\left(\mathbf{m} / \mathbf{s}^{\mathbf{2}}\right)\end{array}$ & $\begin{array}{l}\text { Crest } \\
\text { factor }\end{array}$ & Kurtosis & $\begin{array}{l}\text { Peak } \\
\left(\mathbf{m} / \mathbf{s}^{\mathbf{2}}\right)\end{array}$ & $\begin{array}{l}\text { RMS } \\
\left(\mathbf{m} / \mathbf{s}^{\mathbf{2}}\right)\end{array}$ & $\begin{array}{l}\text { Crest } \\
\text { factor }\end{array}$ & Kurtosis \\
\hline 103 & 0.9024 & 0.3174 & 2.8426 & 2.7009 & 0.9642 & 0.2995 & 3.2195 & 3.2419 \\
153 & 1.0079 & 0.2826 & 3.5660 & 3.2118 & 0.8848 & 0.2785 & 3.1772 & 3.1913 \\
204 & 1.0468 & 0.3139 & 3.3344 & 3.0597 & 1.7222 & 0.2915 & 5.9087 & 4.2642 \\
254 & 1.1174 & 0.3571 & 3.1286 & 2.7831 & 1.3058 & 0.3179 & 4.1080 & 3.3258 \\
303 & 1.2291 & 0.3778 & 3.2538 & 2.6874 & 1.5033 & 0.3269 & 4.5984 & 3.3615 \\
408 & 1.2933 & 0.3970 & 3.2576 & 2.8629 & 1.1084 & 0.3406 & 3.2541 & 2.9627 \\
504 & 1.5600 & 0.4135 & 3.7725 & 3.0958 & 1.1698 & 0.3487 & 3.3545 & 2.8835 \\
602 & 1.5798 & 0.4134 & 3.8218 & 3.0652 & 1.0942 & 0.3568 & 3.0670 & 2.7797 \\
705 & 1.7945 & 0.4734 & 3.7910 & 3.1032 & 1.3001 & 0.3751 & 3.4657 & 2.7847 \\
809 & 2.1781 & 0.5557 & 3.9197 & 3.2691 & 1.4172 & 0.3841 & 3.6894 & 2.8495 \\
901 & 2.0081 & 0.5817 & 3.4524 & 2.9710 & 1.2718 & 0.3824 & 3.3260 & 2.9080 \\
1005 & 1.7738 & 0.5265 & 3.3688 & 2.7392 & 1.2609 & 0.3815 & 3.3051 & 2.8866 \\
1108 & 2.3771 & 0.6214 & 3.8256 & 3.0053 & 1.4285 & 0.3862 & 3.6988 & 3.0514 \\
1211 & & & & & 1.4613 & 0.3857 & 3.7884 & 3.0173 \\
\hline
\end{tabular}

TABLE 2 - Statistical parameters from the laser vibrometer on position 3

\begin{tabular}{ccccc}
\hline $\begin{array}{c}\text { Speed } \\
(\mathbf{r p m})\end{array}$ & $\begin{array}{c}\text { Peak } \\
\left(\mathbf{m} / \mathbf{s}^{\mathbf{2}}\right)\end{array}$ & $\begin{array}{c}\text { RMS } \\
\left(\mathbf{m} / \mathbf{s}^{\mathbf{2}}\right)\end{array}$ & $\begin{array}{c}\text { Crest } \\
\text { factor }\end{array}$ & Kurtosis \\
\hline 103 & 1.2209 & 0.3314 & 3.6838 & 3.8041 \\
254 & 1.6599 & 0.3800 & 4.3681 & 3.9361 \\
408 & 1.5473 & 0.4094 & 3.7797 & 3.3799 \\
504 & 1.5068 & 0.4470 & 3.3708 & 2.9487 \\
705 & 1.8121 & 0.5207 & 3.4804 & 2.9202 \\
809 & 1.9336 & 0.5543 & 3.4882 & 2.8608 \\
901 & 2.0736 & 0.5667 & 3.6593 & 2.9518 \\
1005 & 2.1052 & 0.6060 & 3.4739 & 2.8979 \\
1108 & 2.4470 & 0.6124 & 3.9960 & 3.1657 \\
1211 & 2.0985 & 0.6260 & 3.3523 & 2.9403 \\
\hline
\end{tabular}

TABLE 3. Statistical parameters from the Accelerometer with SVAN 958 on position 1 and 2

\begin{tabular}{ccccccccc}
\hline \multicolumn{3}{c}{} & \multicolumn{3}{c}{ Position 1 } & \multicolumn{3}{c}{ Position 2 } \\
\hline $\begin{array}{c}\text { Speed } \\
(\mathbf{r p m})\end{array}$ & $\begin{array}{c}\text { Peak } \\
\left(\mathbf{m} / \mathbf{s}^{\mathbf{2}}\right)\end{array}$ & $\begin{array}{c}\text { RMS } \\
\left(\mathbf{m} / \mathbf{s}^{\mathbf{2}}\right)\end{array}$ & $\begin{array}{c}\text { Crest } \\
\text { factor }\end{array}$ & Kurtosis & $\begin{array}{c}\text { Peak } \\
\left(\mathbf{m} / \mathbf{s}^{\mathbf{2}}\right)\end{array}$ & $\begin{array}{c}\text { RMS } \\
\left(\mathbf{m} / \mathbf{s}^{\mathbf{2}}\right)\end{array}$ & $\begin{array}{c}\text { Crest } \\
\text { factor }\end{array}$ & Kurtosis \\
\hline 103 & 2.3193 & 0.8119 & 5.1163 & 4.1163 & 2.2583 & 0.3916 & 5.7666 & 2.8276 \\
153 & 2.6550 & 0.7869 & 4.8109 & 3.5109 & 2.2278 & 0.4240 & 5.2538 & 3.2894 \\
204 & 2.9602 & 0.8503 & 4.0073 & 3.0000 & 3.5400 & 0.4869 & 7.2712 & 4.1779 \\
254 & 3.2654 & 0.9255 & 3.5283 & 2.7224 & 2.8992 & 0.5121 & 5.6609 & 3.0436 \\
303 & 3.5400 & 0.9483 & 3.7331 & 2.6256 & 2.9602 & 0.5599 & 5.2868 & 3.2666 \\
408 & 3.9368 & 1.0721 & 3.6722 & 2.5375 & 3.7231 & 0.7061 & 5.2730 & 3.1944 \\
504 & 4.6997 & 1.1528 & 4.0769 & 2.7119 & 4.7913 & 0.8804 & 5.4420 & 3.1687 \\
602 & 5.1880 & 1.3065 & 3.9709 & 2.7778 & 5.7068 & 1.0690 & 5.3385 & 3.1541 \\
705 & 5.8899 & 1.4773 & 3.9870 & 2.8544 & 5.4321 & 1.2334 & 4.4042 & 3.0514 \\
809 & 7.0801 & 1.6777 & 4.2202 & 2.9162 & 6.7444 & 1.4522 & 4.6443 & 3.0963 \\
901 & 8.1787 & 1.8732 & 4.3662 & 2.9552 & 8.0872 & 1.6964 & 4.7672 & 3.1947 \\
1005 & 9.6130 & 2.1564 & 4.4580 & 2.9606 & 8.9111 & 1.9425 & 4.5875 & 3.1354 \\
1108 & 10.2844 & 2.4220 & 4.2463 & 3.0308 & 9.5825 & 2.2184 & 4.3196 & 3.1021 \\
1211 & 10.9863 & 2.6630 & 4.1256 & 2.9851 & 10.8337 & 2.4171 & 4.4822 & 3.0648 \\
\hline
\end{tabular}


TABLE 4. Statistical parameters from the Accelerometer with SVAN 958 on position 3

\begin{tabular}{ccccc}
\hline $\begin{array}{c}\text { Speed } \\
(\mathbf{r p m})\end{array}$ & $\begin{array}{c}\text { Peak } \\
\left(\mathbf{m} / \mathbf{s}^{\mathbf{2}}\right)\end{array}$ & $\begin{array}{c}\text { RMS } \\
\left(\mathbf{m} / \mathbf{s}^{\mathbf{2}}\right)\end{array}$ & $\begin{array}{c}\text { Crest } \\
\text { factor }\end{array}$ & Kurtosis \\
\hline 104 & 3.9978 & 0.5894 & 6.7831 & 3.6391 \\
300 & 6.7139 & 0.9564 & 7.0199 & 4.5555 \\
502 & 6.4697 & 1.2399 & 5.2178 & 3.2997 \\
707 & 7.0190 & 1.5376 & 4.5650 & 3.0538 \\
910 & 7.8125 & 1.7186 & 4.5458 & 2.9911 \\
1093 & 9.3994 & 2.2070 & 4.2590 & 2.9949 \\
1208 & 10.1624 & 2.2709 & 4.4750 & 3.0356 \\
1276 & 10.5286 & 2.4026 & 4.3822 & 3.0684 \\
\hline
\end{tabular}

\section{DISCUSSION}

It has been shown that it is possible to use accelerometers attached to the SVAN 958 to obtain the time domain vibration signal (see figure 1) from the bearing housing. The laser which is an optical method (see figure 2) was also used to obtain the time domain vibration signal (see figure 2). The advantage of the laser is that mass is not added to the system by placing accelerometers on the system as such the dynamics of the system is not altered. The advantage of the SVAN 958 is that it is a very portable device and also cheap to acquire.

The data obtained from the accelerometers which were connected to the SVAN 958 were processed using MATLAB based software to obtain the statistical parameters such as the peak, RMS, crest factor and kurtosis which are tabulated as shown in tables 1 and 2. It can be seen that the kurtosis starts at about 4 which shows the bearing is damaged. Similarly, the data obtained from the laser which is an optical device was equally processed and the statistical parameters such as the peak, RMS, crest factor and kurtosis were obtained and tabulated as shown in table 3 and 4 . Again, it can be seen that the kurtosis starts at about 4 which confirms the damage in the bearing.

Trending at various speed ranging from around $100 \mathrm{rpm}$ to about $1300 \mathrm{rpm}$ was done for the measurents at position 1, position 2 and position 3 and plotted in figures 4 and 5 the data measured using accelerometers attached to the SVAN 958 and the laser respectively. It was seen that there is good correlation for all the three positions were able to pick up the dynamics of the damaged bearing closely as shown by the trending in figures 4 and 5 for the accelerometer and laser data plots respectively. Hence for bearing damage measurement can be done at any of the three positions as indicated in figure 1. Also, even though the accelerometers were placed vertically on the bearing housing in the radial direction and the laser beam placed horizontally in the radial direction, the trend in the statistical parameters is the same as shown in figures 4 and 5 respectively. This then means that again for bearing damage the transducers can be placed vertically or horizontally and the same results could be obtained. At low speeds the incipient bearing damage was picked up as shown by kurtosis values of about 4 . However at high speed of about $1000 \mathrm{rpm}$, the kurtosis value had dropped to about 3. Hence, the bearing damage was not picked up by the kurtosis values as shown in figures 4 and 5. The RMS values increases consistently from around $100 \mathrm{rpm}$ to abour $1200 \mathrm{rpm}$ as shown in figures 4 and 5. Hence, at high speeds the RMS value is able to predict damage better than the kurtosis value. 
(a)

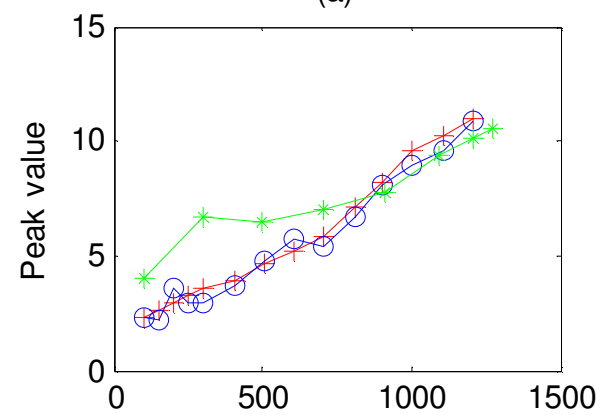

(c)

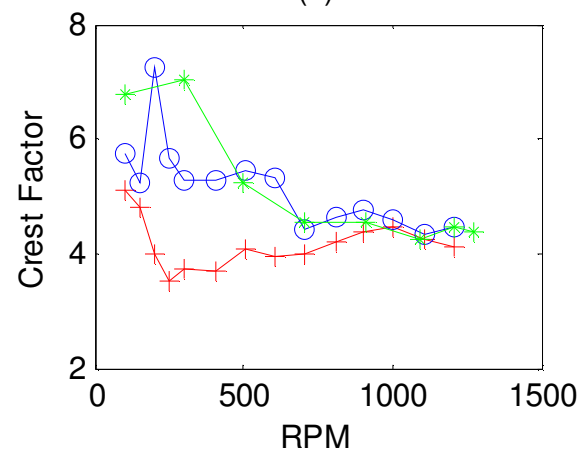

(b)

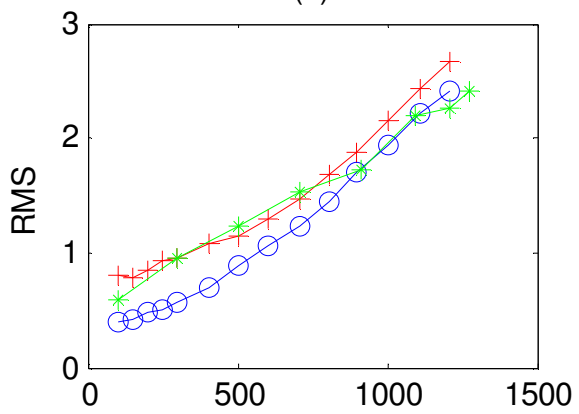

(d)

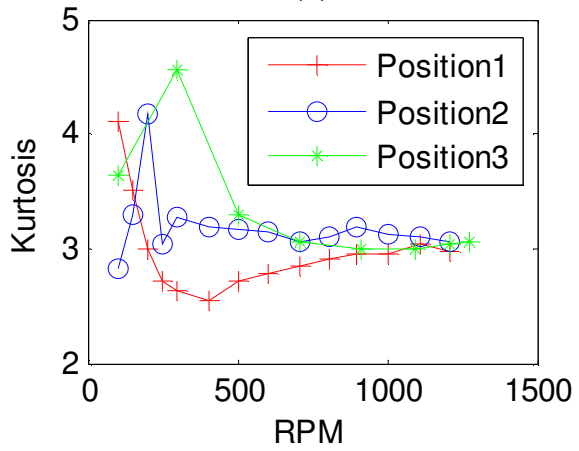

FIGURE 4. Trending of Accelerometer data attached to SVAN 958 (a) Peak values, (b) RMS, (c) Crest Factor and (d) Kurtosis

(a)

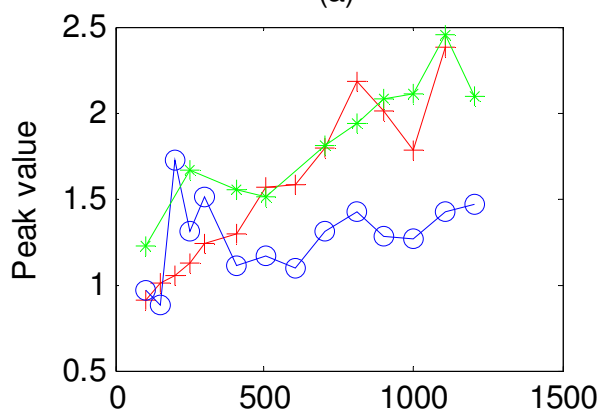

(c)

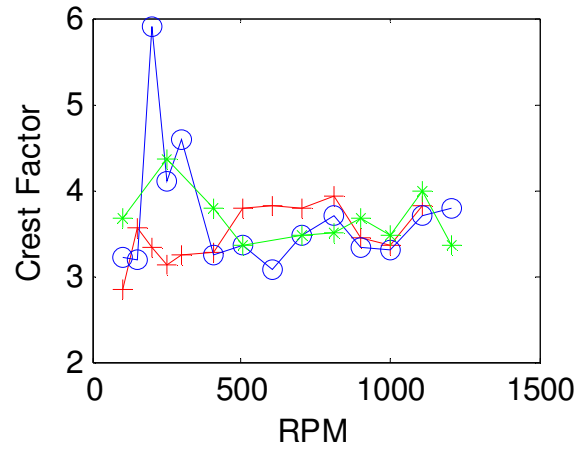

(b)

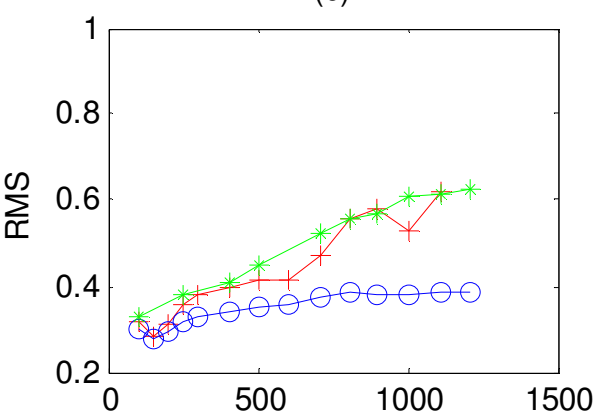

(d)



FIGURE 5. Trending of data from laser (a) Peak values, (b) RMS, (c) Crest Factor and (d) Kurtosis 


\section{CONCLUSION}

The data obtained by using the SVAN 958 and laser methods in measuring bearing vibration was processed to detect damage of the bearing. There was good correlation at the three positions as they able to pick up the dynamics of the damaged bearing closely from trending analysis. Hence it was concluded bearing damage measurement can be done at any of the three positions in the vertical or horizontal direction. The kurtosis picks up incipient bearing damage at low speeds whereas the RMS picks up bearing damage better at higher speeds. Hence, at high speeds the RMS value is able to predict damage better than the kurtosis value. It was established that both methodologies were able to detect damage in the bearing effectively.

\section{REFERENCES}

1. Qiu H. , Lee J. , Lin J. and Yu G., "Robust performance degradation assessment methods for enhanced rolling element bearing prognostics", Advanced Engineering Informatics, 17:127-140 (2003).

2. Heng R.B.W. and Nor M.J.M., "Statistical Analysis of Sound and Vibration Signals for Monitoring Rolling Element Bearing Condition", Applied Acoustics, 53, No. 1-3:21 1-226 (1998).

3. Dyer D. and Stewart R.M., "Detection of rolling element bearing damage by statistical vibration analysis", Design Engineering Technical Conference of ASME, Chicago III, September 20-30, 1978.

4. Valliapan R. and Lieu D.K., "Defect characterization of roller bearing surfaces with laser Doppler vibrometry", Precision Engineering, 14, No. 1:35-42 (1992).

5. Dzwonkowski A., and Swędrowski L., "Laser measurements in the motor bearing diagnostics", Exploring New Frontiers of Instrumentation and Methods for Electrical and Electronic Measurements, 16th IMEKO TC4 Symposium, Florence, Italy, September. 22-24, 2008.

6. Aye S.A. and Heyns P.S., "Evaluation of operator whole body vibration and shock exposure on excavators used in an open cast mine based on ISO 2631-1 and 2631-5", Seventh South African Conference on Computational and Applied Mechanics, University of Pretoria, January, 10-13, 2010.

7. Dempsey, P.J., Certo, J.M., Handschuh, R.F. and Dimofte, F., "Hybrid bearing prognostic test rig”, NASA TM-2005-213597. 